\title{
Hippocampal lesions and delayed alternation in the rat
}

RONALD J. RACINE AND DANIEL P. KIMBLE ${ }^{1}$

UNIVERSITY OF OREGON

\begin{abstract}
Abstraet
Rats were trained preoperatively on a delayed alternation task in which the delay period was increased until $\mathrm{S}$ accumulated four errors at a given delay interval. When the temporal limit for an S was thus determined, $\mathrm{S}$ was given either a bilateral hippocampal lesion or a bilateral cortical lesion. Postoperatively, the hippocampectomized Ss were totally unable to perform the delayed alternation task, even at extremely brief delays. The cortically damaged Ss showed no deficit, all improving on their preoperative temporal limit. These results confirmed and extended previous results with hippocampectomized monkeys.
\end{abstract}

\section{Problem}

The hypothesis that the hippocampus is involved in "recent memory" (Penfield \& Milner, 1958) has not received consistent support from laboratory studies with animals (Kimble, 1963; Mahut \& Cordeau, 1963; Madsen \& Kimble, 1965).

On the other hand, laboratory studies of monkeys with medial temporal lobe-hippocampal removals (Orbach, Milner \& Rasmussen, 1960; Mahut \& Cordeau, 1963; Rosvold \& Szwarcbart, 1964; Pribram, Wilson \& Conners, 1962) have pointed to delayed alternation deficits as particularly conspicuous postoperative results.

The present study investigated the effects of hippocampal lesions on the temporal limits of retention of a delayed alternation task in rats, using Petrinovich \& Bolles method (1961). If the hippocampus is involved in recent memory, the lesion effect should become increasingly apparent as the delay period is extended.

\section{Method}

The Ss were 30 experimentally naive, 60 day old, male Sprague-Dawley rats. The apparatus consisted of a T-maze with an $48 \times 4-1 / 2 \times 6$ in stem, $24 \times 4-1 / 2$ $\mathrm{x} 6$ in arms, and two detachable $12 \times 6 \times 6$ in goal boxes. Ss were placed on a $23 \mathrm{hr}$. water deprivation schedule and gentled for two days. They were then given four trials/day for two days in a straight alley alternately attached to each goal box. $\mathrm{S}$ was allowed 1 min. of drinking on each trial. Ss were then given two free and two forced trials each day for three more days to insure that they would have entered each goal arm $50 \%$ of the time prior to the beginning of alternation training.

Maze training. Phase 1. Ss were run three trials/day using a noncorrection method. They were allowed 20 sec. drinking following each correct response and were detained for $20 \mathrm{sec}$. in the goal boxafter each incorrect response. The first choice of each day was rewarded regardless of the side chosen. The second and third choices were rewarded only if $\mathrm{S}$ alternated its last response. This training was continued for 28 days with an intertrial interval of $10 \mathrm{~min}$.

Phase 2. The 10 Ss which alternated most consistently continued into Phase 2. The same procedure was followed except that the intertrial interval was extended, first to $20 \mathrm{~min}$., then to $40 \mathrm{~min}$., then to $1 \mathrm{hr}$., and then in $1 / 2 \mathrm{hr}$. intervals. If $\mathrm{S}$ alternated without error for two consecutive days, it was advanced to the next longer delay interval. When an animal accumulated four errors at an interval, it was considered to have failed and surgery was then performed on that $\mathrm{S}$. The surgical procedure was similar to that reported previously (Kimble, 1963).

Phase 3. Phase 3 was initiated 10 days following surgery. The procedure was identical to that of Phase 1. Each $\mathrm{S}$ was tested with a $10 \mathrm{~min}$. intertrial interval until its performance in 10 consecutive trials was equal to its performance of the last 10 trials of Phase 1 . When this criterion was reached, Sadvanced to Phase 4, which was identical to Phase 2.

An examination of the sectioned brains revealed extensive (50-90\%) and bilateral hippocampal lesions in all the hippocampectomized Ss.

The brains of the cortically lesioned Ss revealed bilateral damage to neocortex, and no hippocampal damage except for a slight surface invasion in one S (Fig. 1).
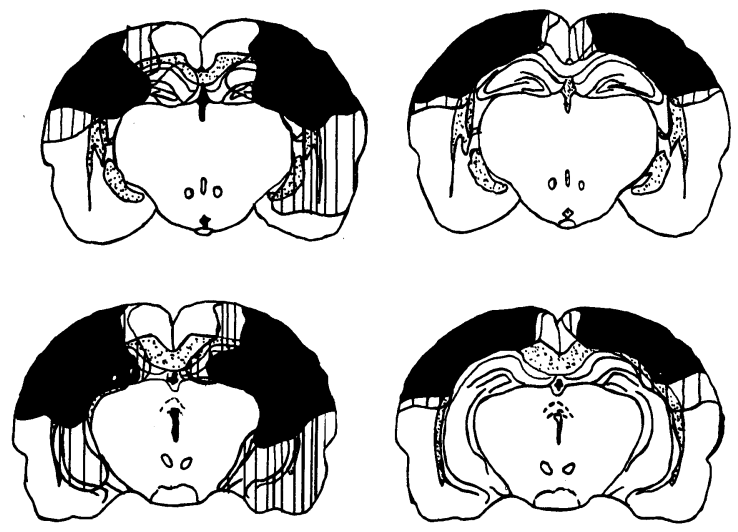

(a)

(b)

Fig. 1. Reconstruction of hippocampal (a) and cortical (b) lesions. Black area indicates minimal lesion extent, lined area indicates maximal lesion extent. 
TABLE I

Delayed Alternation Temporal Limits and Total \% Correct

\begin{tabular}{ccc} 
Rat No. & \multicolumn{2}{c}{ Temporal Limit in min. and (total \% correct) } \\
\cline { 2 - 3 } $\begin{array}{c}\text { Cortical Lesion } \\
\text { Ss }\end{array}$ & Preoperative & Postoperative \\
\cline { 2 - 2 } 3 & $90(73.5)$ & $150(82.3)$ \\
5 & $120(76.3)$ & $180(85.4)$ \\
7 & $120(75.0)$ & $\star$ \\
8 & $180(91.6)$ & $\star$ \\
9 & $210(82.1)$ & $240(82.1)$ \\
\hline
\end{tabular}

Hippocampal Lesion

$\begin{array}{ccc}\text { Ss } & & \\ 1 & 40(68.7) & \text { fail }(30.2) \\ 2 & 60(77.2) & \text { fail }(30.0) \\ 4 & 120(83.3) & \text { fail }(6.2) \\ 6 & 120(76.4) & \text { fail }(25.0) \\ 10 & 330(88.7)^{\star \star} & \text { fail }(46.2)\end{array}$

* died during surgery

** did not fail, testing discontinued at 51/2 hr. interval

\section{Results}

The $10 \mathrm{Ss}$ with the highest alternation scores during Phase 1 were chosen to continue training. Table 1 shows the pre- and postoperative performance of each animal. Postoperatively, all of the cortically lesioned Ss immediately reached their preoperative performance level of Phase 2 within the minimum number of trials necessary. However, none of the hippocampectomized Ss ever approached their preoperative level, during 20 days (60 trials) at delay intervals of $10 \mathrm{~min}$. The delay interval was then lowered to approximately 5-10 sec. (excluding drinking time, Ss being replaced in the start box immediately after each trial) in order to determine if alternation behavior could be obtained under these conditions. It could not. Ss were run an additional 20 days (60 trials) with this short delay. The level of alternation behavior ranged from 5-37\% at the $10 \mathrm{~min}$. delay, and 0-55\% at the $10 \mathrm{sec}$.delay among the hippocampectomized Ss. The number of days of $100 \%$ alternation behavior, i.e., two consecutive alternations, did not increase for any of these Ss, remaining at less than $5 \%$ for $4 / 5$ Ss even at the $10 \mathrm{sec}$. delay. This result indicates that even at < 10 sec. delays, the hippocampectomized Ss were incapable of performing the alternation task. For example, S No. 10, who had never failed preoperatively, failed postoperatively, even at the 10 sec. interval. Each cortically lesioned S extended its preoperative temporal limit following surgery.

\section{Diseussion}

The complete failure of the hippocampectomized Ss to perform the delayed alternation task contrasts with the total lack of effect seen in the cortically lesioned Ss. The present study thus confirms for the rat the results of Mahut \& Cordeau (1963), Orbach, Milner \& Rasmussen
(1960), Pribram et al (1962) and Rosvold \& Szwarcbart (1964) with monkeys, that medial temporal lobe-hippocampal ablations impair delayed alternation behavior. The exact reason for this result, however, is not completely clear. While "recent memory loss" cannot be dismissed as a possible interpretation, the hippocampectomized animals showed no consistent improvement at even very short delay periods, as might be predicted from this hypothesis.

Another possible interpretation is that of "response perseveration"' (Ellen \& Wilson, 1963; Mahut \& Cordeau, 1963). Evidence for this effect was seen at the $10 \mathrm{~min}$. delay; three of the five temporal lobe-hippocampal Ss fixating on a position habit. However, only one S remained fixated at the shorter delay period, while the other Ss displayed a random response pattern.

Kimble \& Pribram (1963) have shown that hippocampal lesions in the monkey interfere with "sequential responding," and that response perseveration may only be one manifestation of such a deficit. Since the delayed alternation task constitutes a simple behavior sequence, our results are compatible with this interpretation, although conclusions regarding the functional role of the hippocampus must remain tentative.

\section{References}

Ellen, $\mathbf{P}$, \& Wilson, A. S. Perseveration in the rat following hippocampal lesions Exp. Neurol., 1963, 8, 310-317.

Kimble, D. P. The effects of bilateral hippocampal lesions in rats. J. comp. physiol. Psychol., 1963, 56, 273-283.

Kimble, D P., \& Pribram, K. H. Hippocampectomy and behavior sequences. Science, 1963, 139, 824-825.

Madsen, M. C., \& Kimble, D. P. The maze behavior of hippocampectomized rats under massed and distributed trials. Psychon. Sci., 1965, 3,

Mahut, Helen, \& Cordeau, J. P. Spatial reversal deficit in monkeys with amygdalohippocampal ablations. Exp. Neurol., 1963, 7, 426-434.

Orbach, J., Milner, Brenda, \& Rasmussen, T. Learning and retertion in monkeys after amygdala-hippocampus resection. Arch. Neurol., 1960, 3, 230-251.

Penfield, W., \& Milner, Brenda. Memory deficit produced by bilateral lesions in the hippocampal zone. Arch. Neurol. Psychiat, 1958, 79, 475-497.

Petrinovich, L., \& Bolles, R. Delayed alternation: evidence for symbolic processes in the rat. J. comp. physiol. Psychol., 1957, $50,363-365$.

Pribram, K. H., Wilson, W. A., \& Conners, Jane. Effects of lesions of the medial forebrain on alternation behavior of rhesus monkeys Exp. Neurol., 1962, 6, 36-47.

Rosvold, H. E., \& Szwarcbart, Maria K. Neural structures involved in delayed-response performance. In J. M. Warren, and K. Akert, (Eds.), The frontal, granular cortex and behavior. New York: McGraw-Hill, 1964. Pp. 1-15.

\section{Note}

1. This research was supported by USPHS Grant No. 08545-02, D. P. Kimble, principal investigator, and by an undergraduate NSF grant to $\mathrm{R}$. J. Racine. 